\title{
Apresentação
}

\section{0 anos do sistema de saúde brasileiro: o Sistema Único de Saúde}

\section{| Célia Regina Pierantoni |}

O tema central desta edição de Physis registra os 20 anos do Sistema Único de Saúde (SUS), formalizado pelo artigo constitucional da "saúde como direito de todos e dever do Estado".

Considerado o maior programa de inclusão social do mundo, o SUS vem-se desenvolvendo ao longo desses 20 anos, independentemente de governos e partidos políticos, expansões e contrações no seu financiamento ou mudanças de modelo na gestão governamental. Tem como base a descentralização e participação social em seu modelo primeiro de gestão, o que tem representado um constante aprendizado institucional na configuração do Estado democrático brasileiro em seu desenho federativo.

Desta forma, Jairnilson Paim inaugura o tema focalizando a reforma sanitária brasileira nas vertentes de movimento e processo. Analisa, à luz de referenciais teóricos, a mudança do sistema de saúde brasileiro como proposta, projeto e processo de reforma social. Estabelece como "hipótese concorrente" um conjunto de dez proposições formuladas por cientistas sociais e militantes do movimento sanitário, contribuindo para ampla e atual exposição e análise do tema.

Em um segundo momento, Ana Luiza Viana e Cristiani Machado analisam os 20 anos do SUS a partir de dimensões selecionadas para a caracterização da proteção social em saúde no caso brasileiro. Focalizam as principais transformações e dificuldades observadas nos últimos anos em cinco eixos relevantes para a proteção social em saúde: centralização-descentralização; organização institucional; financiamento; mix público-privado e modelo de atenção em saúde, apresentando, ainda, os desafios atuais relacionados à expansão da proteção social em saúde no Brasil.

No terceiro artigo, são apresentadas as questões relacionadas ao trabalho e aos trabalhadores da saúde. O tema "recursos humanos" (RHS) entra na agenda 
estratégica de governos e, no Brasil, culmina com a criação da Secretaria de Gestão da Educação e do Trabalho no Ministério da Saúde, em 2002. Após revisão recente sobre o tema, apresentam-se os resultados de pesquisa coordenada por mim e colaboradores sobre o "estado da arte" do olhar RHS em Secretarias estaduais e municipais de Saúde de grandes centros urbanos, apontando limites, acúmulos e possibilidades que se apresentam para apoiar as esferas subnacionais no Brasil na implementação das diretrizes de qualificação do trabalho e do trabalhador da saúde.

Fugindo ao formato do editorial de nossa revista, além dos artigos temáticos, registro neste espaço a transcrição de um documento considerado um marco para a reforma sanitária brasileira, apresentado pelo Centro Brasileiro de Estudos de Saúde (CEBES - Nacional) em outubro de 1979, no 1o Simpósio sobre a Política Nacional de Saúde na Câmara Federal.

A pertinência dessa transcrição busca, num primeiro plano, recuperar historicamente a autoria do mesmo, escrito pelos professores Hésio Cordeiro, José Luis Fiori e Reinaldo Guimarães, do Instituto de Medicina Social da UERJ à época. Em um segundo plano, visa a instigar a capacidade de reflexão dos leitores sobre as propostas contidas no documento-base e a atualidade do sistema de saúde brasileiro.

\section{A Questão Democrática na Área da Saúde}

É praticamente consensual entre os especialistas o diagnóstico de que, a partir da década de 60, vem piorando gradativamente o nível de vida da população. Aumentaram significativamente a mortalidade infantil, as doenças endêmicas, as taxas de acidentes de trabalho, o número de doentes mentais, etc. Pioraram, igualmente, as condições de saneamento, a poluição ambiental e os níveis nutricionais chegaram ao ponto de preocupar as autoridades, hoje um tanto pessimistas com relação ao que chamaram de "miséria absoluta".

Cresce a um só tempo a mobilização popular contra o desemprego, os baixos salários e suas péssimas condições de vida. Cresce também, e mais especificamente, a irritação da população contra as filas, a burocracia, a corrupção e os custos da má atenção médica que recebem. Crescem, finalmente, as reclamações e reivindicações sindicais contra os convênios e contratos com as empresas médicas.

Enquanto isso acontece, a medicina brasileira vive uma profunda crise. Exacerbam-se as críticas à sua qualidade. Questiona-se cada vez mais a sua eficácia. 
Acusam-se os médicos de desleixo e desnaturada avidez salarial. Os donos de hospitais ameaçam fechá-los porque seus lucros estão baixando.

É neste contexto que se situa a maior parte do material que vem sendo veiculado pelos meios de comunicação de massa. Inúmeros elementos objetivos sustentam a parcial veracidade destas acusações. Entretanto, o que só recentemente está vindo à luz, em forma ainda um tanto encoberta, são as reais causas das distorções detectadas. As raízes últimas na anarquia instaurada na assistência médica e da insolvência sanitária da população: a mercantilização da medicina promovida em forma consciente e acelerada por uma política governamental privatizante, concentradora e anti-popular.

Política que substitui a voz da população pela sabedoria dos tecnocratas e pelas pressões dos diversos setores empresariais; política de saúde que acompanha em seu traçado as linhas gerais de posicionamento socioeconômico do governo: privatizante, empresarial e concentrador da renda, marginalizando cerca de $70 \%$ da população dos benefícios materiais e culturais do crescimento econômico. Política de saúde, ainda, que reduziu ao mínimo os gastos em saúde pública, privilegiando a assistência médico-hospitalar curativa e de alta sofisticação, ainda quando o quadro sanitário do país indique a enorme importância dos "velhos" problemas: esquistossomose, Chagas, malária, desnutrição, altos índices de mortalidade infantil, combinados com a emergência de novos padrões de mortalidade urbana (câncer, doenças cardiovasculares, acidentes, violências, etc.). Política de saúde, enfim, que esquece as necessidades reais da população e se norteia exclusivamente pelos interesses da minoria constituída e confirmada pelos donos das empresas médicas e gestores da indústria da saúde em geral.

Exemplo recente desta forma de política elitista e anti-popular é a tentativa de criação do cheque-consulta, cujo único objetivo é satisfazer os interesses dos produtores de serviços, acenando à população com a ilusão de um melhor acesso aos serviços de saúde.

Face a esta política de caráter essencialmente anti-democrático, a grande maioria dos profissionais de saúde encontra-se hoje colocada na trincheira de uma batalha inglória, a tentar remediar os males de um planejamento ineficaz para uma população carente e subnutrida, com técnicas às vezes tão ou mais perigosas que as próprias doenças que deseja eliminar. 
Por outro lado, a população, marginalizada das decisōes sobre a política de saúde da mesma forma que da maioria das decisões sobre a vida nacional, financia um sistema que muito pouco ou nada lhe oferece em troca.

Frente a este quadro, é dever da população e dos profissionais de saúde, nos locais de trabalho e reunidos em torno de suas entidades representativas, apresentar seu diagnóstico da situação. Mais ainda, somando-se ao clima de debates que hoje caracteriza a conjuntura política nacional, avançar e propor plataformas de luta que busquem reunir suas aspirações na linha de constituição de uma medicina democrática.

É neste sentido que o Centro Brasileiro de Estudos de Saúde vem apresentar sua contribuição a este debate e a esta luta.

- O diagnóstico apresentado já indica as grandes linhas de uma proposta, limitando responsabilidades e definindo os principais obstáculos que se interpõem hoje, no Brasil, entre os ideais democráticos e as possibilidades de resposta e adequação real do nosso sistema de saúde àqueles ideais.

Por uma saúde autenticamente democrática entende-se:

1 - o reconhecimento do direito universal e inalienável, comum a todos os homens, à promoção ativa e permanente de condições que viabilizem a preservação de sua saúde.

2 - o reconhecimento do caráter sócio-econômico global destas condições: emprego, salário, nutrição, saneamento, habitação e preservação de níveis ambientais aceitáveis.

3 - o reconhecimento da responsabilidade parcial, porém intransferível, das ações médicas propriamente ditas, individuais e coletivas, na promoção ativa da saúde da população.

4 - o reconhecimento, finalmente, do caráter social deste Direito e tanto da responsabilidade que cabe à coletividade e ao Estado em sua representação, pela efetiva implementação e resguardo das condições supra mencionadas.

Por isso, são necessárias medidas que:

1 - obstaculizem os efeitos mais nocivos das leis de mercado na área de saúde, ou seja, detenham o empresariamento da medicina.

2 - transformem os atos médicos lucrativos em um bem social gratuito a disposição de toda a população.

3 - criem um Sistema Único de Saúde. 
4 - atribuam ao Estado a responsabilidade total pela administração desse Sistema.

5 - deleguem ao Sistema Único de Saúde a tarefa de planificar e executar uma política nacional de saúde, que inclua: a pesquisa básica, a formação de recursos humanos, a atenção médica individual e coletiva, curativa e preventiva, o controle ambiental, o saneamento e a nutrição mínima à sobrevivência de uma população hígida.

6 - estabeleçam mecanismos eficazes de financiamento do sistema, que não sejam baseados em novos gravames fiscais sobre a maioria da população, nem os novos impostos específicos para a saúde. O financiamento do Sistema Único deverá ser baseado numa maior participação proporcional do setor saúde nos orçamentos federal, estaduais e municipais, bem como no aumento da arrecadação decorrente de uma alteração fundamental no atual caráter regressivo do sistema tributário.

7 - organizem este sistema de forma descentralizada, articulando sua organização com a estrutura político-administrativa do país em seus níveis federal, estadual e municipal, estabelecendo unidades básicas, coincidentes ou não com os municípios, constituídas por aglomeraçôes de população que eventualmente reuniriam mais de um município ou desdobrariam outros de maior densidade populacional. Esta descentralização tem por fim viabilizar uma autêntica participação democrática da população nos diferentes níveis e instâncias do sistema, propondo e controlando as ações planificadas de suas organizações e partidos políticos representados nos governos, e assembléias e instâncias próprias do Sistema Único de Saúde.

8 - esta descentralização visa, por um lado, à maior eficácia, permitindo uma maior visualização, planificação e alocação dos recursos segundo as necessidades locais. Mas visa, sobretudo, a ampliar e agilizar uma autêntica participação popular a todos os níveis e etapas na política de saúde.

Este, talvez o ponto fundamental desta proposta, negador de uma solução meramente administrativa ou "estatizante". Trata-se de canalizar as reivindicaçôes e proposiçōes dos beneficiários, transformando-os em voz e voto em todas as instâncias.

Evita-se, também, com isto, uma participação do tipo centralizador tão cara ao espírito corporativista e tão apta às manipulações cooptativas de um Estado fortemente centralizado e autoritário como tem sido tradicionalmente o Estado brasileiro.

9 - estabeleçam um estatuto de convivência entre a prática assalariada vinculada ao Sistema Único de Saúde e a autêntica prática de consultórios particulares que tem tradição na medicina brasileira. 
10 - definam uma estratégia específica de controle sobre a produção e distribuição de medicamentos, assim como de produção e/ou importação de consumo de equipamentos médicos. Que esta estratégia tenha presentes as necessidades reais, majoritárias e regionalizadas da população, reduzindo ao mínimo os gastos e a sofisticação desnecessária.

Estas opçóes políticas conduzem a uma proposta de transformação profunda no atual sistema de saúde cujas medidas iniciais sejam:

I - Criar o Sistema Único de Saúde (SUS).

II - Outorgar ao Ministério da Saúde a direção do SUS, com a tarefa de planificar e implantar, em conjunto com os governos estaduais e municipais, a Política Nacional de Saúde. O órgão deve ter poder normativo e executivo, inclusive sobre o setor privado e empresarial, sendo controlado permanentemente pela população através de suas organizações representativas, via mecanismos claramente estabelecidos e institucionalizados.

III - Definir a Política de Assistência Médica, atualmente levada a cabo pelo Inamps, já então enquadrado e disciplinado pelo órgão diretor do SUS, mediante a suspensão imediata dos convênios e contratos de pagamento por unidades de serviços para a compra de atos médicos ao setor privado empresarial, substituindoos por subsídios globais; estabelecer mecanismos efetivos de controle destas unidades contratadas que impeçam conseqüências danosas como o aviltamento dos salários dos profissionais e a diminuição da qualidade do atendimento; controle a ser exercido em conjunto por um representante do Sistema Único de Saúde com assento permanente na direção destas unidades.

IV - Criar imediata, ainda que progressivamente, com os recursos antes despendidos com os convênios e outros, uma rede nacional, devidamente regionalizada de ambulatórios e postos de saúde próprios, voltados para a aplicação de medidas preventivas, articuladas com a assistência médica primária, de casos de emergência e acidentes do trabalho. Para o funcionamento destes postos, deverão ser utilizados médicos funcionários do Sistema Único e sobretudo pessoal auxiliar, cuja formação deverá ser estimulada com veemência.

$\mathrm{V}$ - Definição de uma política para a área rural adequada às reais necessidades de sua população, descondicionando a prestação de assistência médica da satisfação de interesses eleitorais de grupos partidários. 
VI - Redefinir a atual política do FAS para que passe a funcionar a expansão da rede básica dos serviços de saúde.

VII - Privilegiar as medidas de controle do meio ambiente, particularmente aquelas destinadas à redução de doenças endêmicas, como Chagas, esquistossomose, malária, etc.

VIII - Planejar a formação e distribuição de profissionais de saúde, definindo as prioridades para a formação de pessoal não-especializado e especializado.

IX - Definir uma política de produção e distribuição de medicamentos e equipamentos médicos orientada pela simplificação e eficácia tecnológica e dirigida à redução da dependência ao capital estrangeiro através de:

- maior participação estatal na pesquisa, formação de pesquisadores e desenvolvimento de tecnologia nacional dirigida à produção de matériasprimas fundamentais à industrialização de medicamentos essenciais; de modo similar ao que originalmente propunha o próprio projeto ou Central de Medicamentos;

- controle de remessas de lucros para o exterior;

- controle efetivo da qualidade e da quantidade dos medicamentos comercializados;

- importação apenas daqueles equipamentos e fármacos que tenham tido sua eficácia comprovada através da utilização por um período mínimo de cinco anos.

O conjunto destas reivindicações conforma uma primeira etapa na formulação de uma plataforma de luta em prol de uma autêntica democratização da Medicina e da Saúde Brasileira. Não pretende ser executiva nem abranger detalhamentos administrativos de implementação. Não é seu objetivo. Define apenas as grandes linhas que deverão orientar, em nosso entender, as decisões políticas fundamentais.

Abre-se a partir deste momento um debate democrático, o mais amplo e fértil possível, com todas as entidades e instituiçõos interessadas na solução da crise atual da Medicina Brasileira. Debate que aprofunde estes pontos indicados, levando à formulação mais acabada de uma plataforma que agrupe e mobilize médicos e não-médicos na luta contra a atual política de governo para a saúde e a favor de uma Medicina Democrática.

O CEBES, dentro da perspectiva da democratização dos serviços de saúde, entende também que devam ser atendidas as justas reivindicações dos movimentos sociais no setor no sentido de: 
1 - Desvincular os conselhos profissionais do Ministério do Trabalho, a exemplo da OAB.

2 - Estabelecer salários justos que dignifiquem a atividade profissional, a estabilidade no emprego e melhores condições de trabalho.

3 - Ser coibido o uso do saber e autoridade quando usada para praticar ou acobertar atos de violência física ou moral contra a pessoa humana.

4 - Eliminar toda e qualquer discriminação social, religiosa, política e ideológica na admissão de profissionais para cargos públicos ou privados.

5 - Modificar os atuais currículos de formação de profissionais, adaptando-os às atuais necessidades sociais e enfatizando a área de saúde coletiva.

6 - Regularizar a situação de diferentes profissionais, como por exemplo, assinando a carteira de trabalho para residentes e regulamentando em todos os níveis a carreira de sanitaristas.

7 - Imediata readmissão de professores, médicos, cientistas, etc., atingidos pelos atos excepcionais.

8 - Recusar na sua totalidade o atual projeto da CLT, unindo-se à luta de todos os trabalhadores brasileiros. 